\title{
Small Airway Remodeling in Idiopathic Interstitial Pneumonias: A Pathological Study
}

\author{
George Castro Figueira de Mello ${ }^{a}$ Carlos Roberto Ribeiro Carvalho ${ }^{b}$ \\ Ronaldo Adib Kairalla ${ }^{b}$ Paulo Hilário Nascimento Saldiva ${ }^{a}$ Sandra Fernezlian ${ }^{a}$ \\ Luiz Fernando Ferraz Silva $^{a}$ Marisa Dolhnikoffa ${ }^{\text {Thais Mauad }}{ }^{a}$ \\ a Pathology Department and ' ${ }^{\text {P }}$ ulmonary Division, Hospital das Clinicas, University of Sao Paulo Medical School, \\ São Paulo, Brazil
}

\section{For editorial comment see p. 277}

\section{Key Words}

Interstitial lung disease - Matrix metalloproteinase •

Pneumonia, nonspecific interstitial · Small airways

\begin{abstract}
Background: Few studies have addressed small airway (SA) histopathological changes and their possible role in the remodeling process in idiopathic interstitial pneumonias. $\mathbf{O b}$ jectives: To study morphological, morphometrical and immunohistochemical features of SA in idiopathic pulmonary fibrosis (usual interstitial pneumonia, UIP) and nonspecific interstitial pneumonia (NSIP). Methods: We analyzed SA pathology in lung biopsies from 29 patients with UIP and 8 with NSIP. Biopsies were compared with lung tissue from 13 patients with constrictive bronchiolitis (CB) as positive controls and 10 normal autopsied control lungs. We semi-quantitatively analyzed SA structure, inflammation, architectural features and the bronchiolar epithelial immunohistochemical expression of TGF- $\beta$, MMP-2, 7, 9, and their tissue inhibitors (TIMP-1, 2). Results: Compared to controls, patients with UIP, NSIP and CB presented increased bronchiolar inflammation, peribronchiolar inflammation and fibrosis and decreased luminal areas. UIP patients had thicker walls due to an increase in most airway compartments. NSIP patients presented in-
\end{abstract}

creased epithelial areas, whereas patients with CB had larger inner wall areas. All of the groups studied presented increased bronchiolar expression of MMP-7 and MMP-9, compared to the controls. Conclusion: We conclude that SAs are pathologically altered and may take part in the lung-remodeling process in idiopathic interstitial pneumonias.

Copyright $\odot 2009$ S. Karger AG, Basel

\section{Introduction}

Idiopathic pulmonary fibrosis (IPF), its histopathological correlate usual interstitial pneumonia (UIP), and nonspecific interstitial pneumonia (NSIP) are major entities among the idiopathic interstitial pneumonias (IIPs). Traditionally, these disorders are described as affecting the lung parenchyma diffusely and the alveoli primarily [1]. Lung function tests show a restrictive ventilatory pattern and reduced diffusion capacity associated with normal expiratory flows $[2,3]$.

Earlier histological studies suggested that there is small airway (SA) involvement in interstitial lung diseases (ILDs) $[1,4,5]$. Airway narrowing in ILDs would result in maldistribution of ventilation, which can cause inhomogeneity of impedance and time constants within the

\section{KARGER}

Fax +4161306 1234 E-Mail karger@karger.ch www.karger.com
() 2009 S. Karger AG, Basel 0025-7931/10/0794-0322\$26.00/0

Accessible online at: www.karger.com/res
Thais Mauad

Department of Pathology, Sao Paulo University Medical School

Av. Dr. Arnaldo, 455, room 1155

São Paulo, SP 01246-903 (Brazil)

Tel. +55 113061 7173, Fax +55 113062 8098, E-Mail tmauad@usp.br 
lung, thereby causing a reduction in dynamic compliance and increase the work of breathing, and possibly the sensation of dyspnea [1].

However, it has been more difficult to consistently demonstrate functional signs of airway dysfunction in these diseases. Some authors have described an obstructive pattern at the peripheral level associated with high elastic recoil in all patients, but other studies could not confirm these data [4-6]. Such controversial results have been attributed to the patchy distribution of histological lesions in ILDs and to the increased retractile force observed in fibrotic lungs that would maintain the patency of SA in vivo [1].

In 2002, the ERS/ATS Consensus Classification [2] of the IIPs proposed the current classification based on clinical, radiological and pathological aspects. All previous pathological or functional studies analyzing SA in ILDs were performed long before this classification and may, therefore, have included more than one of the current diseases under the diagnosis of IPF. To our knowledge, no previous studies have analyzed SA involvement in NSIP patients.

In airways diseases such as asthma, the bronchial epithelium plays an active role in the remodeling process, whereas in IIPs alveolar cells are believed to be the major players [7-12]. Previous immunohistochemical studies have shown that alveolar epithelial cells of IIP patients differentially express a wide range of matrix metalloproteinases (MMPs) such as MMP-7, MMP-1, MMP-2, its inhibitors and inducers, creating a delicate balance of extracellular matrix (ECM) destruction and production $[8$, $10-15]$. Transforming growth factor- $\beta$ (TGF $\beta$ ) seems to be a critical mediator of this balance, and alveolar epithelial cells have been shown to have increased expression of TGF $\beta$ in the IIPs $[16,17]$. It is possible that the SA epithelium could participate in the remodeling events taking place in IIPs, since these cells also produce a wide range of cytokines, growth factors and metalloproteinases $[7,8$, 15-17].

For this purpose, we performed a quantitative and semiquantitative analysis of the structural and inflammatory parameters of the SA, including a study of bronchiolar epithelial expression of TGF $\beta$, MMPs and their tissue inhibitors (TIMPs) in open lung biopsies from patients with UIP/IPF and NSIP.

\section{Methods}

This study was approved by the Ethics Committee of the University of Sao Paulo Medical School.
Study Population

Patients with a biopsy-proven diagnosis of UIP and NSIP (1992-2005) were included in the study. Autopsy samples from non-smoker patients, without lung disease and with normal lung histology, were used as negative controls. In order to compare SA alterations found in UIP/NSIP with changes classically observed in a primarily airway disease, we also included biopsies of patients with idiopathic constrictive bronchiolitis (CB) [18].

All diagnoses were supported by history, physical examination, pulmonary function tests and radiological parameters, not associated with any environmental exposure to a fibrogenic agent or connective tissue disorder. Morphological diagnosis was performed according to the ATS/ERS consensus classification [2] after the biopsies were reviewed by 2 experienced pathologists (T.M. and M.D.).

The diagnosis of IPF was only considered when the patient presented no other cause for an ILD, with typical microscopic findings of the UIP pattern and absence of vasculitis, granulomas or microorganisms. Cases presenting extensive honey-combing or dual histological patterns were excluded from the analysis. The diagnosis of cellular or fibrotic NSIP was mainly based on histological findings in patients who had a clinico-radiological picture of ILD, with the histological picture of chronic interstitial pneumonia, in which homogeneous expansion of alveolar septa by inflammation and/or fibrosis was present [19]. We have excluded cases with an associated diagnosis of collagen vascular diseases that manifested at diagnosis or during follow-up of at least 2 years, or any organic dust exposure associated with the development of hypersensitivity pneumonitis (HP).

Patients with idiopathic CB presented obstructive lung function with no known cause and with characteristic tomographic signs, such as a mosaic pattern [18] and lung biopsies showing a picture of $\mathrm{CB}$ without interstitial inflammation or fibrosis.

Patients were not treated with corticosteroids or immunosuppressants by the time the biopsies were performed.

\section{Tissue Processing}

All biopsy and autopsy samples were retrospectively retrieved from the archives of the Department of Pathology, University of Sao Paulo. The material was fixed for $24 \mathrm{~h}$ in buffered formalin and paraffin-embedded.

\section{Immunohistochemistry}

Antigen retrieval and primary antibodies used to label MMPs (MMP-1, 2, and 7), TIMPs (TIMP-1 and 2) and TGF $\beta$ are shown in table 1. Briefly, sections were dewaxed and hydrated. A 3\% $\mathrm{H}_{2} \mathrm{O}_{2}$ solution was applied for $40 \mathrm{~min}$ to inhibit endogenous peroxidase activity, followed by overnight incubation with the primary antibody and antigen retrieval. Anti-mouse secondary antibodies (Vector Laboratories, Burlingame, Calif., USA) were used after the primary antibodies. The streptavidin-biotin complex (LSAB + DakoCytomation, Carpinteria, Calif., USA) was used as the developing system. All sections were stained within one staining session, using antibodies from one batch. For negative controls, the primary antibody was omitted, and substitutions of the primary antibody with an isotype-matched control antibody of the same species and PBS were used as negative controls. 
Table 1. Antibodies and processing used in the immunohistochemical analyses

\begin{tabular}{|c|c|c|c|c|c|}
\hline Antibody & Pre-treatment & Species & Dilution & Clone & Origin \\
\hline TGF $\beta$ & Citrate & Rabbit & $1: 50$ & Polyclonal & Santa Cruz Biotechnology, Santa Cruz, Calif., USA \\
\hline MMP-2 & Citrate & Mouse & $1: 2,500$ & A-Gel VC2 & Lab Vision, Fremont, Calif., USA \\
\hline MMP-7 & Citrate & Mouse & $1: 50$ & $176-5 \mathrm{~F} 12$ & Chemicon, Temecula, Calif., USA \\
\hline MMP-9 & Citrate & Mouse & $1: 100$ & $56-2 \mathrm{~A} 4$ & Calbiochem, Darmstadt, Germany \\
\hline TIMP-1 & TRIS-EDTA & Mouse & $1: 10$ & $7-6 \mathrm{C} 1$ & Calbiochem, Darmstadt, Germany \\
\hline TIMP-2 & Citrate & Mouse & $1: 25$ & $67-4 \mathrm{H} 11$ & Calbiochem, Darmstadt, Germany \\
\hline
\end{tabular}

MMP = Matrix metalloproteinases; TIMP = tissue inhibitor of metalloproteinase

\section{Morphometry and Semiquantitative Analysis}

For morphometrical determinations, 5- $\mu \mathrm{m}$ thick HE sections were used. Quantification was performed in the transversally cut airways, i.e., with a short/long diameter ratio of $>0.6$, and with a basement membrane $(\mathrm{BM})$ perimeter of $<6 \mathrm{~mm}[20]$. We analyzed all suitable $S A s$ in areas of more preserved lung tissue architecture in order to adequately identify the different airway compartments. SAs surrounded by extensive honeycombing and fibrosis were therefore excluded from the analysis. The software ImagePro ${ }^{\circledR}$ Plus 4.1 for Windows ${ }^{\circledR}$ (Media Cybernetics, Silver Spring, Md., USA), running on an microcomputer connected to a digital camera (JVC TK-C1380 Color Video Camera, Victor Company of Japan Limited, Japan) and coupled to an optical microscope (Leica DMR, Leica Microsystems, Wetzlar GmbH, Wetzlar, Germany) was used for the measurements. Analysis was performed in a blinded manner.

The following airway compartments were assessed: luminal area, epithelial area, inner wall area, airway smooth muscle (ASM) area, outer wall area and total wall area. For each airway, the BM perimeter was assessed. Only areas of intact epithelium were evaluated, i.e., a layer of both basal and columnar cells. The inner wall area was defined as the region comprising the epithelial $\mathrm{BM}$ and inner border of the ASM. The outer wall was the region from the outer border of the ASM to the outer border of the adventitia. Values are expressed as area corrected by BM perimeter $\left(\mu \mathrm{m}^{2} / \mu \mathrm{m}\right)$. In order to estimate the percentage of thickened airways in each disease group, we further determined the mean and the standard deviation of total airway thicknesses in controls. For non-control groups, thickened airways were considered to be those with a thickness value larger than the mean plus the standard deviation of the controls in each lung biopsy.

The area of positive staining for each antibody within the bronchiolar epithelium was determined by color threshold. For this purpose, different sections stained with each antibody, as well as negative controls, were used to achieve the best range of positivity in the cases, which was checked by 2 pathologists (G.M. and T.M.). These procedures generated a file containing all color selection data, which were afterwards applied to all cases stained with the same antibody. Results are expressed as the epithelial area of specific antibody staining corrected by the BM perimeter $\left(\mu \mathrm{m}^{2} / \mu \mathrm{m}\right)[20-24]$.

The following parameters were analyzed semiquantitatively: the degree of airway and peribronchiolar parenchymal inflam- mation and fibrosis (peribronchiolar defined as the space within one $100 \times$ field around the bronchiole) was scored as 0-3 (absent, mild, moderate, strong). We also analyzed the presence of intraluminal buds of granulation tissue and mucostasis in the airways. In the peribronchiolar parenchyma, we scored the presence of bronchiolar epithelial metaplasia (lambertosis) [25], cystic spaces (honeycombing) and bronchus-associated lymphoid tissue (BALT). Results are expressed as the number of SAs presenting the above-mentioned alteration in relation to the total number of SAs analyzed per group (\%).

\section{Statistical Analysis}

Demographic, clinical and numerical data are presented as median/interquartile range (IQR) or mean $\pm \mathrm{SD}$, depending on data distribution. Non-normally distributed numerical data were log-transformed before analysis. For comparison of the different disease groups with controls, Student's t test was used as the data had a normal distribution. Comparison among the disease groups was performed with ANOVA, followed by the Bonferroni posthoc test. Data obtained from semiquantitative analysis (bronchiolar inflammation, peribronchiolar parenchymal inflammation, peribronchiolar parenchymal fibrosis) were analyzed using Kruskal-Wallis followed by Mann-Whitney tests (that are non-normally distributed) and are expressed as the median and IQRs. For the analysis of categorical values (mucostasis, intraluminal buds, bronchiolar epithelial metaplasia, cystic spaces and BALTs), the Fisher exact test was performed. The level of significance was set at $\mathrm{p}<0.05$. The statistical package SPSS 13.0 (SPSS, Chicago, Ill., USA) was used for the analyses.

\section{Results}

\section{Patient Population}

Twenty-nine patients with biopsy-proven UIP, 8 with NSIP ( 5 of the cellular pattern, 3 of the fibrosing pattern) and 13 patients with $\mathrm{CB}$ were included in the study. Six patients were excluded from the NSIP group because they were diagnosed as having associated collagen vascular diseases during follow-up. Ten autopsied patients were 
Table 2. Demographic, clinical, functional and tomographic features of the patients included in the study

\begin{tabular}{|c|c|c|c|c|}
\hline & $\begin{array}{l}\text { UIP } \\
(n=29)\end{array}$ & $\begin{array}{l}\text { NSIP } \\
(n=8)\end{array}$ & $\begin{array}{l}\mathrm{CB} \\
(\mathrm{n}=13)\end{array}$ & $\begin{array}{l}\text { Control } \\
(\mathrm{n}=10)\end{array}$ \\
\hline Mean age, years (range)/male sex, $\mathrm{n}$ & $66(49-80) / 18$ & $56(38-69)^{*} / 3$ & $53(31-61)^{*} / 7$ & $54(44-63)^{*} / 5$ \\
\hline Smoking history ${ }^{\mathrm{a}}$ & $16(55.2 \%)$ & $3(37.5 \%)$ & $6(46.2 \%)$ & $0(0 \%)$ \\
\hline Duration of symptoms, months ${ }^{\mathrm{b}}$ & $12(16)$ & $12(30)$ & $5(9.5)$ & - \\
\hline FVC, $\%$ predicted $^{\mathrm{c}}$ & $70.6 \pm 15.1$ & $69.8 \pm 21.5$ & $55.8 \pm 25.7$ & NA \\
\hline $\mathrm{FEV}_{1}, \%$ predicted & $79.5 \pm 15.8^{\#}$ & $78.5 \pm 26.9^{\#}$ & $48.3 \pm 31.2$ & NA \\
\hline $\mathrm{FEV}_{1} / \mathrm{FVC}$ ratio & $0.87 \pm 0.07^{\#}$ & $0.87 \pm 0.05^{\#}$ & $0.64 \pm 0.18$ & NA \\
\hline $\mathrm{FEF}_{25-75}, \%$ predicted & $117.3 \pm 53.1^{\#}$ & $89.7 \pm 21.9$ & $39.3 \pm 36.4$ & NA \\
\hline \multicolumn{5}{|l|}{ Tomographic site of lesions } \\
\hline Central & $0(0 \%)$ & $1(12.5 \%)$ & $0(0 \%)$ & NA \\
\hline Peripheral & $13(45 \%)$ & $2(25 \%)$ & $5(38.5 \%)$ & \\
\hline Diffuse & $16(55 \%)$ & $5(62.5 \%)$ & $8(61.5 \%)$ & \\
\hline \multicolumn{5}{|l|}{ Tomographic pattern of lesions } \\
\hline Reticular opacities & $17(58.6 \%)$ & $1(12.5 \%)$ & $1(7.7 \%)$ & NA \\
\hline Ground glass attenuation & $7(24 \%)$ & $6(75 \%)$ & $2(15.4 \%)$ & \\
\hline Mosaic attenuation & $4(14 \%)$ & $1(12.5 \%)$ & $9(69.2 \%)$ & \\
\hline Consolidation & $1(3.4 \%)$ & $0(0 \%)$ & $1(7.7 \%)$ & \\
\hline Honeycombing & $20(69 \%)$ & $2(25 \%)$ & $1(8 \%)$ & \\
\hline
\end{tabular}

Unless otherwise indicated, the values are the number of patients with percentages in parentheses. FVC = Forced vital capacity; $\mathrm{FEV}_{1}=$ forced expiratory volume in $1 \mathrm{~s} ; \mathrm{FEF}_{25-75}=$ forced expiratory flow in $25-75 \%$ of FVC; UIP = usual interstitial pneumonia; NSIP = nonspecific interstitial pneumonia; $\mathrm{CB}=$ chronic bronchiolitis; NA $=$ not available.

${ }^{*} \mathrm{p}<0.05$ in relation to UIP; ${ }^{*} \mathrm{p}<0.05$ in relation to CB.

${ }^{a}$ Current and ex-smokers.

${ }^{\mathrm{b}}$ Duration of symptoms expressed as median (IQR).

${ }^{c}$ Lung function tests expressed as mean $\pm \mathrm{SD}$.

included as controls. Demographic, clinic, functional and tomographic data are shown in table 2. Patients with UIP/IPF were significantly older than all other study groups $(p=0.02)$. There was no difference among the disease study groups in smoking frequency. Patients with $\mathrm{CB}$ had a significantly lower $\mathrm{FEV}_{1}(\mathrm{p}=0.01), \mathrm{FEV}_{1} / \mathrm{FVC}$ $(\mathrm{p}=0.001)$ and $\mathrm{FEF}_{25-75}(\mathrm{p}=0.003)$ than all other study groups. There were no significant differences in the duration of symptoms (until biopsy) among groups.

\section{Morphological and Morphometrical Analysis}

Biopsy samples included 1-3 slides/patient taken from lung areas with differing disease involvement. A total of 409 SAs were analyzed: 168 in UIP biopsies (6/case); 29 in NSIP biopsies (4/case); 74 in CB (6/case), and 138 in the control group (14/case).

Representative examples of the studied pathologies are presented in figure 1.

Semiquantitative and categorical data are presented in table 3. All disease groups presented more intense bron- chiolar and peribronchiolar parenchymal inflammation and peribronchiolar parenchymal fibrosis than the controls $(\mathrm{p}=0.0001)$. When the disease groups were compared among each other, patients with UIP presented smaller levels of bronchiolar inflammation than NSIP and CB cases $(p=0.01)$. Peribronchiolar parenchymal inflammation was more prominent in patients with NSIP, which differed significantly from all other disease groups $(\mathrm{p}=0.0001)$. There was more peribronchiolar parenchymal fibrosis in UIP and NSIP cases than in CB cases $(\mathrm{p}=$ 0.0002).

When compared to controls, the diseased groups showed an increased degree of mucostasis, bronchiolar epithelial metaplasia, cystic spaces and BALT $(p=0.03)$. Patients with CB had more intraluminal buds than the controls $(p=0.04)$. When the diseased groups were compared among each other, there was no significant difference in the frequency of intraluminal buds. There was less bronchiolar epithelial metaplasia in patients with $\mathrm{CB}$ than patients with NSIP and UIP $(\mathrm{p}=0.0001)$. As expect- 
Fig. 1. Representative examples of control airways (A) and small airway involvement in usual interstitial pneumonia (UIP; B), nonspecific pneumonia (NSIP; C) and constrictive bronchiolitis (CB; D) cases. There is a varying degree of small airway inflammation and fibrosis in UIP, NSIP and $\mathrm{CB}$, with prominent inflammation in the NSIP case and airway fibrosis in UIP and CB. Note the fibroblastic foci (c) and arterial wall thickening (a) in the UIP case (B). The NSIP case shows the typical homogeneous thickening of the alveolar septa (as) due to prominent inflammation. The bronchiole wall (b) is thickened due to fibrosis with the formation of bronchusassociated lymphoid tissue (BALT) aggregate in the CB (D). A The alveolar septa (as) are normal. A-D HE. Scale bar $=200 \mu \mathrm{m}$.
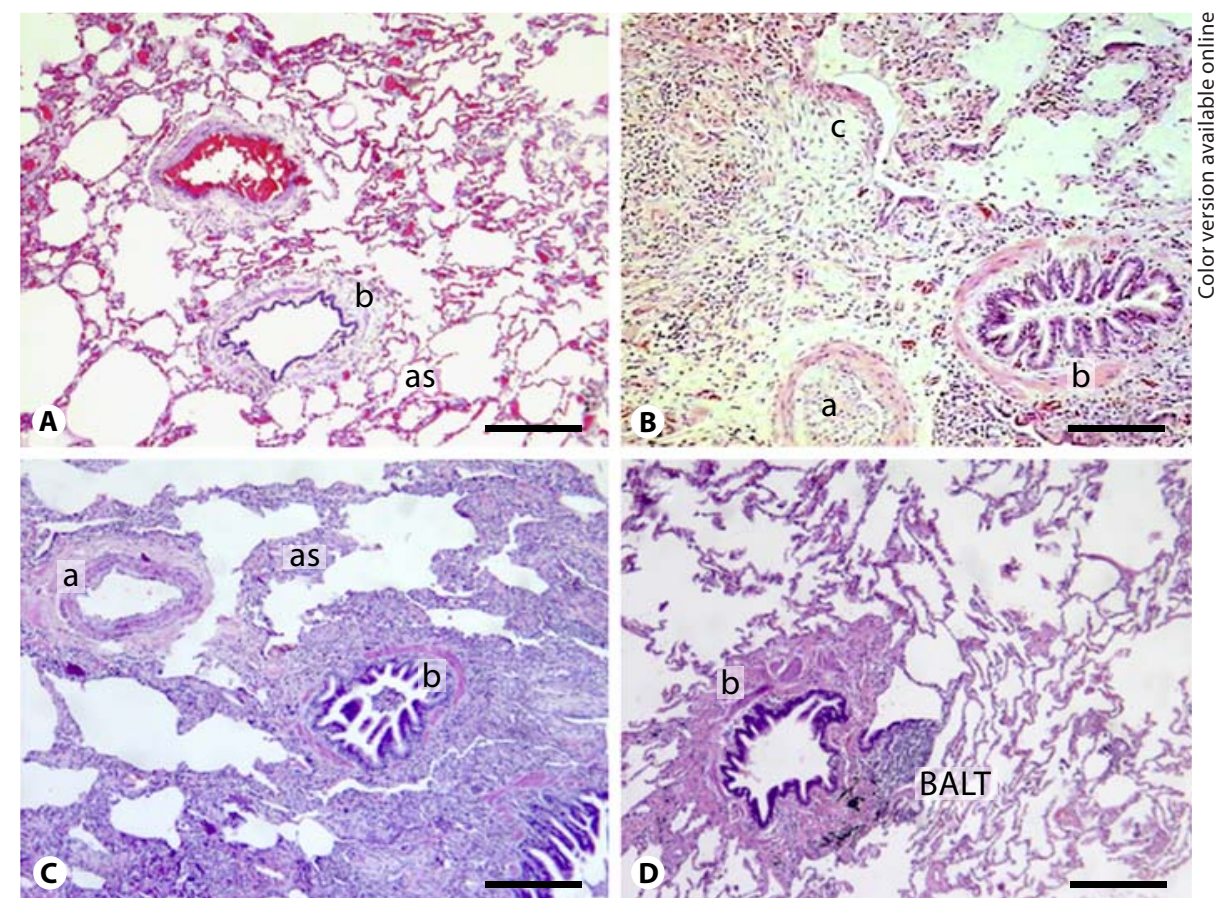

ed, patients with UIP had more cystic spaces than the other disease groups $(p=0.03)$. Data are presented in table 3 .

\section{Quantitative Data}

The BM perimeter was 2,216.5 $\pm 783.1 \mu \mathrm{m}$ in the UIP group, $1,831.8 \pm 406.2 \mu \mathrm{m}$ in the NSIP group, 1,602.3 \pm $494.1 \mu \mathrm{m}$ in the CB cases, and 1,594.1 $\pm 415.1 \mu \mathrm{m}$ in the controls. Although all measured airways were classified as SA, i.e., with $\mathrm{BM}$ of $<6.0 \mathrm{~mm}$, the mean $\mathrm{BM}$ perimeter in the UIP and the NSIP cases was larger than in the control and CB cases (UIP only; $\mathrm{p}=0.03$ ). According to Weibel [26], the mean airway diameters corresponded to airway generations $14-15$, i.e., terminal bronchioles, in all study groups. The luminal areas in all of the study groups were smaller than the controls $(\mathrm{p}=0.0001)$.

Patients with UIP presented larger epithelial, inner wall, ASM, outer and total airway areas than the controls $(\mathrm{p}=0.02)$. In NSIP patients, there was an increased area of epithelium compared to controls $(\mathrm{p}=0.02)$. Patients with $\mathrm{CB}$ presented larger inner wall areas than control patients $(\mathrm{p}=0.04)$.

When the diseases were compared among each other, there were no significant differences among airway compartments, except for outer wall areas, which were larger in UIP patients than in NSIP and CB patients $(\mathrm{p}=0.04)$, and the total area was larger in the UIP than the $\mathrm{CB}$ group $(\mathrm{p}=0.04)$. Data are presented in table 4 .

The percentage of remodeled, thickened SAs was $48.8 \%$ in the UIP group, $41.4 \%$ in the NSIP group and $32.4 \%$ in the $\mathrm{CB}$ group.

\section{Immunohistochemistry}

In some cases, paraffin blocks were not available or there was not enough material for further sectioning; therefore immunohistochemical analysis was performed in a smaller number of cases (table 5).

In controls, TGF $\beta$ was expressed in the bronchiolar epithelium and vascular smooth muscle, whereas in the disease groups, inflammatory cells and alveolar pneumocytes were also positive. MMP-2 was expressed in SA epithelial and mesenchymal cells, endothelium and macrophages in the controls as well as in the studied pathologies. In controls, MMP-7 was weakly expressed in the bronchiolar epithelium and macrophages. In the diseased groups, especially in the UIP group, there was marked expression in the bronchiolar epithelium, mesenchymal cells, reactive pneumocytes and vessels. MMP-9 was expressed in neutrophils, macrophages and weakly in the SA epithelium of controls, with stronger expression in the 
Table 3. Small airway (SA) semiquantitative and categorical histopathological data

\begin{tabular}{|c|c|c|c|c|}
\hline Variable & UIP & NSIP & $\mathrm{CB}$ & Control \\
\hline Bronchiolar inflammation $^{\mathrm{a}}$ & $1.25(0.43)^{*}$ & $1.55(0.87)^{*, \#}$ & $1.5(1.05)^{*, \#}$ & $0.00(0.05)$ \\
\hline Peribronchiolar parenchymal inflammation ${ }^{\mathrm{a}}$ & $1.50(0.92)^{*}$ & $2.41(0.85)^{*, \#}$ & $1.0(1.17)^{*, \#,+}$ & $0.00(0.00)$ \\
\hline Peribronchiolar parenchymal fibrosis ${ }^{\mathrm{a}}$ & $1.40(1.00)^{*}$ & $2.00(2.20)^{*}$ & $0.4(0.75)^{*, \#,+}$ & $0.00(0.00)$ \\
\hline Mucostasis ${ }^{\mathrm{b}}$ & $60(35.7 \%)^{*}$ & $7(24.1 \%)^{*}$ & $17(23 \%)^{*}$ & $3(2.2 \%)$ \\
\hline Intraluminal buds ${ }^{\mathrm{b}}$ & $2(1.2 \%)$ & 0 & $3(4.1 \%)^{*}$ & 0 \\
\hline Bronchiolar epithelial metaplasia ${ }^{\mathrm{b}}$ & $94(56 \%)^{*}$ & $19(65.5 \%)^{*}$ & $17(23 \%)^{*, \#,+}$ & 0 \\
\hline Cystic spaces ${ }^{\mathrm{b}}$ & $58(34.5 \%)^{*}$ & $2(6.9 \%)^{*, \#}$ & $8(10.8 \%)^{*, \#}$ & 0 \\
\hline BALT $^{b}$ & $81(48.2 \%)^{*}$ & $9(31 \%)^{*}$ & $32(43.2 \%)^{*}$ & $19(13.8 \%)$ \\
\hline
\end{tabular}

The semiquantitative variables were scored as 0-3 (absent, mild, moderate, severe) and expressed as the median and interquartile ranges (IQR). The categorical data are expressed as the number of SA presenting the analyzed variable in relation to the total number of analyzed SA per group, in percentages. UIP $=$ Usual interstitial pneumonia; NSIP = nonspecific interstitial pneumonia; $\mathrm{CB}=$ chronic bronchiolitis; $\mathrm{BALT}=$ bronchusassociated lymphoid tissue.

${ }^{*} \mathrm{p}<0.05$ in relation to control; ${ }^{*} \mathrm{p}<0.05$ in relation to UIP; ${ }^{+} \mathrm{p}<0.05$ in relation to NSIP.

a Semiquantitative data. ${ }^{\mathrm{b}}$ Categorical data.

Table 4. Morphometrical data on small airway structure

\begin{tabular}{lllll}
\hline & UIP & NSIP & CB & Control \\
\hline Luminal area & $37.9 \pm 32.2^{*}$ & $26.6 \pm 13.7^{*}$ & $25.4 \pm 11.3^{*}$ & $80.2 \pm 28.4$ \\
Epithelial area & $23.6 \pm 8.3^{*}$ & $23.3 \pm 7.8^{*}$ & $21.3 \pm 9.3$ & $14.8 \pm 5.8$ \\
Inner wall area & $23.4 \pm 11.4^{*}$ & $18.4 \pm 12.8$ & $18.5 \pm 12.0^{*}$ & $10.7 \pm 5.7$ \\
Airway smooth muscle area & $28.5 \pm 14.1^{*}$ & $25.9 \pm 18.5$ & $23.3 \pm 16.1$ & $19.4 \pm 7.9$ \\
Outer wall area & $71.3 \pm 36.2^{*}$ & $40.2 \pm 15.2^{\#}$ & $46.4 \pm 25.6^{\#}$ & $34.2 \pm 15.4$ \\
Total area & $147.0 \pm 60.3^{*}$ & $108.0 \pm 39.1$ & $109.7 \pm 58.1^{\#}$ & $79.2 \pm 29.5$ \\
\hline
\end{tabular}

Values are expressed as mean $\pm \mathrm{SD}$ of area $\left(\mu \mathrm{m}^{2}\right)$ corrected by basement membrane perimeter $(\mu \mathrm{m})$. UIP $=$ Usual interstitial pneumonia; NSIP = nonspecific interstitial pneumonia; $\mathrm{CB}=$ chronic bronchiolitis.

${ }^{*} \mathrm{p}<0.05$ in relation to control; ${ }^{*} \mathrm{p}<0.05$ in relation to UIP.

Table 5. Small airway bronchiolar epithelial expression of transforming growth factor- $\beta$ (TGF $\beta$ ), matrix metalloproteinases (MMP) and tissue inhibitor of metalloproteinases (TIMP)

\begin{tabular}{lclll}
\hline Antibodies & UIP $(\mathrm{n}=11)$ & NSIP $(\mathrm{n}=5)$ & CB $(\mathrm{n}=9)$ & Control $(\mathrm{n}=10)$ \\
\hline TGFß & $1.38 \pm 1.2$ & $0.83 \pm 0.4$ & $1.11 \pm 0.7$ & $0.89 \pm 0.7$ \\
MMP-2 & $0.49 \pm 0.3^{*}$ & $0.39 \pm 0.3$ & $1.00 \pm 0.6^{+}$ & $0.67 \pm 0.4$ \\
MMP-7 & $10.21 \pm 7.7^{*}$ & $8.60 \pm 4.9^{*}$ & $5.59 \pm 5.4^{*}$ & $1.42 \pm 1.6$ \\
MMP-9 & $8.19 \pm 5.5^{*}$ & $7.51 \pm 4.0^{*}$ & $6.46 \pm 4.3^{*}$ & $0.06 \pm 0.0$ \\
TIMP-1 & $2.87 \pm 2.7$ & $2.28 \pm 1.3$ & $4.95 \pm 2.7$ & $2.13 \pm 0.9$ \\
TIMP-2 & $3.37 \pm 3.5$ & $1.83 \pm 1.8$ & $3.72 \pm 3.8^{*}$ & $0.79 \pm 0.6$ \\
\hline
\end{tabular}

Values are expressed as mean $\pm \mathrm{SD}$ of the positive epithelial area/BM length $\left(\mu \mathrm{m}^{2} / \mu \mathrm{m}\right) . \mathrm{UIP}=\mathrm{Usual}$ interstitial pneumonia; NSIP = nonspecific interstitial pneumonia; $\mathrm{CB}=$ chronic bronchiolitis.

${ }^{*} \mathrm{p}<0.05$ in relation to control; ${ }^{+} \mathrm{p}<0.05$ in relation to NSIP. 


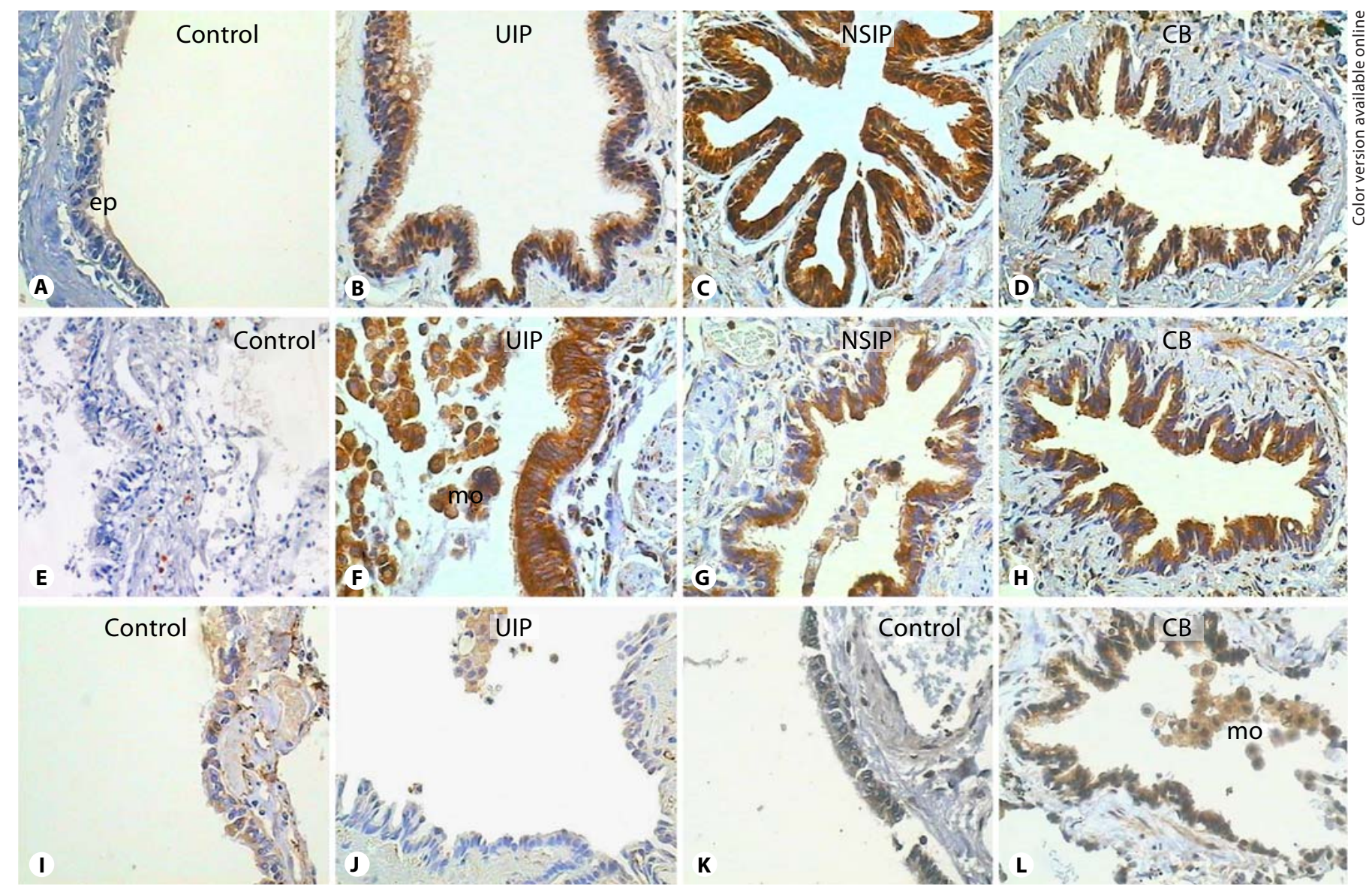

Fig. 2. A-D There is increased SA epithelial expression (ep) of matrix metalloproteinase (MMP)-7 in the usual interstitial pneumonia (UIP; B), non-specific pneumonia (NSIP; C) and constrictive bronchiolitis (CB; D) cases in relation to the control cases $(\mathbf{A})$. $\mathbf{E}-\mathbf{H}$ Epithelial bronchiolar expression of MMP-9 is also increased in the UIP (F), NSIP $(\mathbf{G})$ and CB (H) cases when compared to the

control (E). Scattered inflammatory cells and intraluminal macrophages (mo) are positive for MMP-7 and MMP-9. I, J There is decreased SA epithelial expression of MMP-2 in UIP (J) as compared to the control (I). K, L CB cases (L) present increased SA epithelial expression of the tissue inhibitor of metalloproteinase (TIMP)-2 compared to control (K). Scale bar $=25 \mu \mathrm{m}$.

bronchiolar epithelium, endothelial cells and pneumocytes in the other groups. TIMP-1 and 2 were expressed in inflammatory cells, mainly macrophages, and in vessels (smooth muscle layer and variable on endothelium). They were weakly expressed in the bronchiolar epithelium in both groups. In the disease groups, further expression was observed in reactive pneumocytes and mesenchymal cells.

When compared to the controls, all study groups presented increased expression of MMP-7 $(\mathrm{p}=0.02)$ and MMP-9 ( $\mathrm{p}=0.0002)$ in the bronchiolar epithelium (fig. 2). There was increased expression of TIMP-2 in patients with CB in comparison to controls $(\mathrm{p}=0.02)$. UIP patients presented decreased expression of MMP-2 in the

bronchiolar epithelium when compared to controls $(\mathrm{p}=$ 0.04). There were no differences in the expression of TGF $\beta$ and TIMP-1 among groups. Data are presented in table 5 .

No differences among the studied parameters were observed between smokers and non-smokers in all disease groups. Log of MMP-7 epithelial expression correlated significantly with $\log$ of $\mathrm{FEF}_{25-75}(\mathrm{r}=0.83, \mathrm{p}=0.01)$ in UIP patients (fig. 3). No other significant correlations between pathological and clinical/functional parameters were identified. 


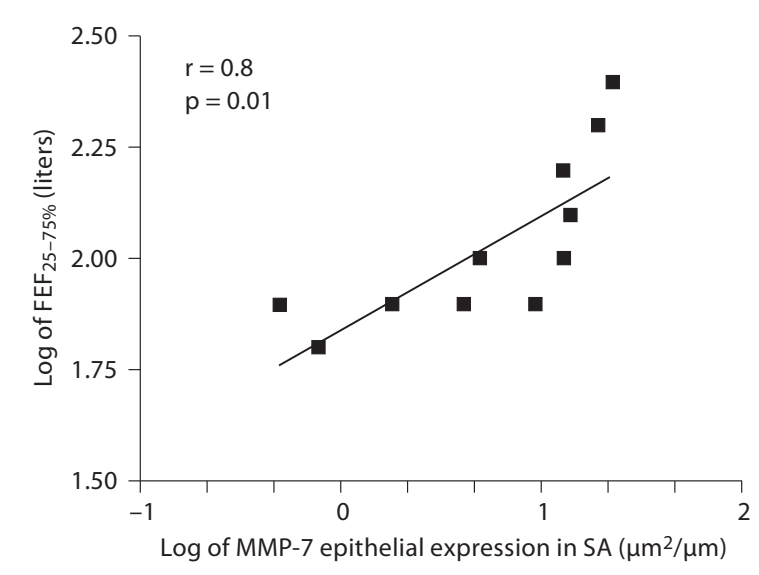

Fig. 3. Graphic correlation of MMP-7 expression in small airways of patients with usual interstitial pneumonia and $\mathrm{FEF}_{25-75 \%}$ predicted values.

\section{Discussion}

Our data show that significant inflammatory and structural alterations at the SA level are present in patients with UIP and NSIP. Novel information provided by this study is related to the increased expression of MMP9 and MMP-7 in the bronchiolar epithelium, suggesting that SA may take part in the pathogenetic events leading to lung remodeling in the IIPs.

This is the first study quantitatively analyzing SA involvement in IIP cases classified according to the current ATS/ERS consensus classification [2]. Similar studies date back to the 1980s and 1990s $[5,27,28]$ and analyzed SA histology by semiquantitative scores only. Most of them included patients who, in light of current knowledge, most likely presented different fibrotic disorders or had interstitial pneumonias associated with other clinical conditions, such as collagen vascular diseases. In the study by Fulmer et al. [5], for instance, 5 of 18 patients were younger than 40 years making the diagnosis of IPF/ UIP in these individuals unlikely.

To our knowledge, this is also the first study to analyze SA involvement in cases of NSIP. This is still a provisional category, probably representing a common histopathological pattern of different ILDs [2]. To avoid systemic/local influences of an underlying disease in the lungs, we have included only patients with an idiopathic form of the disease. Our quantitative and semiquantitative findings indicate that more prominent SA structural alterations seem to occur in the UIP cases than in NSIP. Interestingly, the SA inflammation score was smaller in the UIP cases. Conversely, the inflammatory component was more prominent in the NSIP cases, with a similar magnitude as the $\mathrm{CB}$ at the airway level and an increased magnitude at the peribronchial parenchymal level.

In the lung interstitium, it is well known that the NSIP cases may have a more prominent alveolar inflammatory component than UIP $[2,29]$. Taken together, it is possible to speculate that SA changes occur parallel to alveolar changes in NSIP and UIP patients [27]. It is very likely that SA alterations are more prominent in areas of extensive parenchymal fibrosis, and related to the areas of traction bronchiectasis/bronchiolectasis observed in CT scans [30]. In the present study we analyzed SA in more preserved areas of the lungs, avoiding regions with extensive fibrosis and lung distortion, and detected structural alterations in these regions as well. Taken together, our data point to the possibility that SA involvement occurs as part of disease pathogenesis, and is not solely related to the effects of smoking, past exposures, collagen vascular diseases, or is not merely an expansion of the parenchymal fibrosis.

Our findings of increased MMP-7 and 9 immunohistochemical expressions in SA suggest that the bronchiolar epithelium may contribute to remodeling events occurring in the IIPs. Recently, in an experimental model of bleomycin-induced fibrosis, Wu et al. [31] demonstrated that bronchial epithelial cells have the capacity to undergo epithelial mesenchymal transition, reinforcing the idea that the bronchiolar epithelium may contribute to mesenchymal expansion in pulmonary fibrosis. The increased expression of MMPs without an associated increase in the TIMPs and TGF $\beta$ at the bronchiolar level in UIP and NSIP suggests that, as possibly opposed to that described in the lung parenchyma, a degradative environment prevails at the bronchiolar epithelial level in these diseases [12].

MMP-7 (matrylisin) has been implicated as a possible mediator of pulmonary fibrosis, and the MMP-7 gene is one of the genes that is most distinctive between fibrotic and normal lungs [14, 32, 33]. MMP-2 (gelatinase A) and MMP-9 (gelatinase B) expression is also consistently elevated in the lung parenchyma of NSIP and UIP [10-12, 14]. Here, we demonstrate that the bronchiolar epithelium immunohistochemical expression of MMP-7 and MMP-9 is equally upregulated in UIP and NSIP. This is in line with recent findings presented by Vuorinen et al. [34], who showed similar bronchoalveolar lavage levels of MMP-7 in cases of UIP, sarcoidosis and NSIP. MMP-7 
may play a dual role in ILDs: it can contribute to matrix degradation, and it can also be involved in epithelial migration and repair $[13,35]$. Interestingly, in this study, we found a positive correlation of $\mathrm{FEF}_{25-75}$ and MMP-7 expression in the UIP cases.

Patients with UIP presented with decreased expression of bronchiolar epithelium of MMP-2 (gelatinase A) when compared to controls. The reasons for such a finding are not clear, but may be related to disease progression in IPF. In animal models of bleomycin-induced fibrosis, there is early expression and activity of the gelatinases that is further substituted by an elevation in their inhibitors $[36,37]$. Additionally, a recent study in aged rats demonstrated a decrease in lung MMP-1 and MMP-2 activity when compared to younger animals [38]. Since IPF patients were older than the control group, decreased MMP-2 expression could be related to aging.

Smoking seems to be a risk factor in the development of lung fibrosis [39], and some of our patients were current or ex-smokers. We compared both groups to check for any influence of cigarette smoking in our findings, but no significant difference in the diverse parameters was found. It is possible that the influence of smoking on SA pathology is more evident in the early phases of the diseases than in an advanced phase, such as presented by our patients.

Previous studies in patients with lung transplantationassociated bronchiolitis obliterans have shown increased levels of MMPs and TIMPs in bronchoalveolar fluids, suggesting a role for these proteins as disease markers. In this study, we now show that, in patients with idiopathic $\mathrm{CB}$, there is an increase in MMP-7, MMP-9 and TIMP-2 expression in the bronchiolar epithelium, suggesting that these proteins may also be involved in disease pathogenesis in this entity.

Interestingly, a recent study on familial pulmonary fibrosis patients with early ILD demonstrated that some of these patients presented lung biopsies with interstitial diseases with histological involvement of the SA, such as organizing pneumonia and HP [39]. In patients with chronic HP, the presence of inflammatory and structural alterations in SA is part of the pathological definition of this entity $[27,40]$. Although restrictive ventilatory abnormalities are the predominant functional alterations in HP, signs of airway obstruction have been described as a long-term functional outcome in farmer's lung $[3,41]$. Previously, Myre et al. [28] detected signs of peripheral airway obstruction and peribronchial fibrosis in 8 of 11 biopsies from patients with early stage IPF. These data suggest that SA involvement may already occur in the earlier phases of the disease, which may have important pathogenetic implications.

The relation of structure-function in the SAs in IIPs has not yet been clarified. The controversial functional results related to SA function are likely to be explained by the heterogeneity of the patients studied, the irregular distribution of the lesions, and differences in age, clinical diagnosis, smoking status, and lung function methodologies [1]. It is interesting to note that, despite having thickened airway walls with decreased airway lumens, IPF and NSIP patients in this study did not present clear airway disease functionally, at least in the most conventional methods of assessing lung function. Our study shows that airway structural alterations in the IIPs seem to affect a different percentage of the SAs, which can contribute to explaining the lack of functional changes. A similar functional phenomenon is described in the syndrome of combined pulmonary fibrosis and emphysema, characterized by subnormal or normal spirometry despite severe emphysema and pulmonary fibrosis on chest imaging [42, 43].

Diffuse alveolar fibrosis leads to severe ventilatory restriction and decrease in lung compliance and lung volumes. The extension of fibrosis to peribronchiolar tissue may possibly determine a decrease in airway compliance and loss of bronchiolar-parenchyma interdependence. In obstructive lung diseases, functional changes, such as air trapping and decrease in $\mathrm{FEV}_{1}$, result from normal or increased lung compliance and tissue overdistension associated with reduced elastic recoil pressure. It is possible that severe alveolar fibrosis determines such a decrease in lung compliance and lung volumes such that elastic recoil pressure can be increased. In this case, the obstructive effect of airway fibrosis would be masqueraded by lung restriction. Indeed, it has been suggested that the increased retractile force observed in fibrotic lungs would maintain the patency of SA in vivo $[1,4,6,30,44]$. It is possible that a more detailed functional evaluation directed to SA could demonstrate the physiological changes secondary to these important morphological alterations.

Our study has certainly limitations. Because it is very difficult to have access to normal lung tissue in nonsmoking patients, we have used autopsy samples as controls. We acknowledge that postmortem changes may have influenced our data, such as the expression of some proteins by immunohistochemistry. However, we have been careful to process the autopsy material with adequate fixation and timing in order to avoid loss of antigenicity. Using immunohistochemistry we have previously 
published adequate results in autopsy and biopsy material [45]. In cases of UIP and NSIP, the basement membrane perimeter was higher than in controls and $\mathrm{CB}$ groups. It is possible that in UIP and NSIP cases, bronchioles of higher generation were included in the fibrotic collapsed areas and hence were not suitable for analysis. Although all studied SAs could be classified as terminal bronchioles according to Weibel's classification [26], and SA areas were normalized to BM perimeter, we cannot exclude that this may have induced a bias in the analysis of the results with the bronchioles of IIP patients appearing thicker.

In summary, we have shown that patients with IPF and NSIP present inflammatory and structural changes at the
SA level and that the bronchiolar epithelium may participate in the remodeling events taking place in these diseases. It is essential to learn more about SA structure function in ILDs to better understand the functional significance of SA disease in these disorders.

\section{Acknowledgements}

This research was funded by FAPEMA (Fundação de Amparo à Pesquisa e ao Desenvolvimento Cientifico e Tecnológico do Maranhão), LIM HC-FMUSP and CNPq (Conselho Nacional de Desenvolvimento Científico e Tecnológico). The funding covered the costs related to scholarships and technical supplies for the pathological studies.

\section{References}

$\checkmark 1$ Chung MP, Rhee CH: Airway obstruction in interstitial lung disease. Curr Opin Pulm Med 1997;3:332-335.

-2 American Thoracic Society, European Respiratory Society: International multidisciplinary consensus classification of the idiopathic interstitial pneumonias. Am Respir Crit Care Med 2002;165:277-304

3 Chetta A, Marangio E, Olivieri D: Pulmonary function testing in interstitial lung diseases. Respiration 2004;71:209-213.

4 Ostrow D, Cherniack RM: Resistance to airflow in patients with diffuse interstitial lung disease. Am Rev Respir Dis 1973;108:205210.

-5 Fulmer JD, Roberts WC, Von Gal ER, Crystal RG: Small airways in idiopathic pulmonary fibrosis - comparison of morphologic and physiologic observations. J Clin Invest 1977; 60:595-610.

-6 Schofield NM, Davies RJ, Cameron IR, Green M: Small airways in fibrosing alveolitis. Am Rev Respir Dis 1976;113:729-735.

7 Holgate ST, Lackie P, Wilson S, Roche W, Davies D: Bronchial epithelium as a key regulator of airway allergen sensitization and remodeling in asthma. Am J Respir Crit Care Med 2000;162:S113-S179.

$\checkmark 8$ Gueders MM, Foidart JM, Noel A, Cataldo DD: Matrix metalloproteinases (MMPs) and tissue inhibitors of MMPs in the respiratory tract: potential implications in asthma and other lung diseases. Eur J Pharmacol 2006; 533:133-144.

-9 Holgate ST: Epithelium dysfunction in asthma. J Allergy Clin Immunol 2007;12:12331244.

10 Suga M, Iyonaga K, Okamoto T, Gushima Y, Miyakawa H, Akaike T, Ando M: Characteristic elevation of matrix metalloproteinase activity in idiopathic interstitial pneumonias. Am J Respir Crit Care Med 2000;162: 1949-1956.
11 Fukuda Y, Ishizaki M, Kudoh S, Kitaichi M, Yamanaka N: Localization of matrix metalloproteinases-1, -2, and -9 and tissue inhibitor of metalloproteinase- 2 in interstitial lung diseases. Lab Invest 1998;78:687-698.

12 Selman M, Ruiz V, Cabrera S, Segura L, Ramirez R, Barrios R, Pardo A: TIMP-1, -2, -3 , and -4 in idiopathic pulmonary fibrosis. A prevailing nondegradative lung microenvironment? Am J Physiol Lung Cell Mol Physiol 2000;279:562-574.

13 Cosgrove GP, Schwarz MI, Geraci MW, Brown KK, Worthen GS: Overexpression of matrix metalloproteinase-7 in pulmonary fibrosis. Chest 2002;121:25S-26S.

14 Selman M, Pardo A, Barrera L, Estrada A, Watson SR, Wilson K, Aziz N, Kaminski N, Zlotnik A: Gene expression profiles distinguish idiopathic pulmonary fibrosis from hypersensitivity pneumonitis. Am J Respir Crit Care Med 2006;173:188-198.

15 Odajima N, Betsuyaku T, Nasuhara Y, Itoh T, Fukuda Y, Senior RM, Nishimura M: Extracellular matrix metalloproteinase inducer in interstitial pneumonias. Hum Pathol 2006; 37:1058-1065.

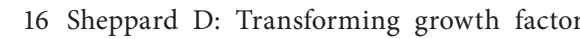
beta: a central modulator of pulmonary and airway inflammation and fibrosis. Proc Am Thorac Soc 2006;3:413-417.

17 Khalil N, O'Connor RN, Unruh HW, Warren PW, Flanders KC, Kemp A, Bereznay $\mathrm{OH}$, Greenberg AH: Increased production and immunohistochemical localization of transforming growth factor-beta in idiopathic pulmonary fibrosis. Am J Respir Cell Mol Biol 1991;5:155-162.

18 Visscher DW, Myers JL: Bronchiolitis: the pathologist's perspective. Proc Am Thorac Soc 2006;3:41-47.
19 Visscher DW, Myers JL: Histologic spectrum of idiopathic interstitial pneumonias. Proc Am Thorac Soc 2006;3:322-329.

20 Mauad T, Xavier ACG, Saldiva PHN, Dolhnikoff $\mathrm{M}$ : Elastosis and fragmentation of fibers of the elastic system in fatal asthma. Am J Respir Crit Care Med 1999;160:968-975.

21 Hogg JC, Chu F, Utokaparch S, Woods R, Elliott WM, Buzatu L, Cherniack RM, Rogers RM, Sciurba FC, Coxson HO, Paré PD: The nature of small-airway obstruction in chronic obstructive pulmonary disease. N Engl J Med 2004;350:2645-2653.

22 Bai A, Eidelman DH, Hogg JC, James AL, Lambert RK, Ludwig MS, Martin J, McDonald DM, Mitzner WA, Okazawa M, Pack RJ, Pare PD, Schellenberg RR, Tiddens HAWM, Wagner EM, Yager D: Proposed nomenclature for quantifying subdivisions of the bronchial wall. J Appl Physiol 1994;7:10111014.

23 De Boer WI, Hiemstra PS, Sont JK, De Heer E, Rabe KF, Van Krieken JHJM, Sterk PJ: Image analysis and quantification in lung tissue. Clin Exp Allergy 2001;31:504-508.

24 Sont JK, De Boer WI, Van Schadewijk WAAM, Grunberg K, Van Krieken JHJM, Hiemstra PS, Sterk PJ; Asthma Management Project University of Leiden Study Group: Fully automated assessment of inflammatory cell counts and cytokine expression in bronchial tissue. Am J Respir Crit Care Med 2003;167:1496-1503.

25 Cordier JF: Challenges in pulmonary fibrosis 2: bronchiolocentric fibrosis. Thorax 2007;62:638-649.

26 Weibel ER: Design of airways and blood vessels considered as branching trees; in Barnes PJ, Weibel ER, West JB, Crystal RG (eds): The Lung - Scientific Foundations, ed 2. Philadelphia, Lippincott-Raven, 1997, pp 10611071. 
-27 Padilla RP, Gaxiola M, Salas J, Mejia M, Ramos C, Selman M: Bronchiolitis in chronic pigeon breeder's disease - morphologic evidence of a spectrum of small airway lesions in hypersensitivity pneumonitis induced by avian antigens. Chest 1996;110:371-377.

$\checkmark 28$ Myre M, Allard S, Bernard C, Martin RR: Clinical, functional and pathological correspondence in early stage idiopathic pulmonary fibrosis: evidence for small airway obstruction 1-2. Respiration 1988;53:174-186.

-29 Flaherty KR, Martinez FJ: Nonspecific interstitial pneumonia. Semin Respir Crit Care Med 2006;27:652-658.

30 Wilcox AG: Small airway involvement in in terstitial lung disease: radiologic evidence. Curr Opin Pulm Med 2000;6:399-403.

-31 Wu Z, Yang L, Cai L, Zhang M, Cheng X, Yang X, Xu J: Detection of epithelial to mesenchymal transition in airways of a bleomycin induced pulmonary fibrosis model derived from an $\alpha$-smooth muscle actin-Cre transgenic mouse. Respir Res 2007;8:1.

\32 Dunsmore SE, Saarialho-Kere UK, Roby JD, Wilson CL, Matrisian LM, Welgus HG, Parks WC: Matrilysin expression and function in airway epithelium. J Clin Invest 1998; 102:1321-1331.

-33 Zuo F, Kaminski N, Eugui E, Allard J, Yakhini Z, Ben-Dor A, Lollini L, Morris D, Kim Y, DeLustro B, Sheppard D, Pardo A, Selman M, Heller RA: Gene expression analysis reveals matrilysin as a key regulator of pulmonary fibrosis in mice and humans. Proc Natl Acad Sci USA 2002;99:6292-6297.
34 Vourinen K, Myllarniemi M, Lammi L, Piirila P, Rytila P, Salmenkivi K, Kinnula V: Elevated matrilysin levels in bronchoalveolar lavage fluid do not distinguish idiopathic pulmonary fibrosis from other interstitial lung diseases. APMIS 2007;115:969-975.

35 Parks WC, Lopez-Boado YS, Wilson CL: Matrilysin in epithelial repair and defense. Chest 2001;120:36-41.

36 Manoury B, Caulet-Maugendre S, Guénon I, Lagente V, Boichot E: TIMP-1 is a key factor of fibrogenic response to bleomycin in mouse lung. Int J Immunopathol Pharmacol 2006; 19:471-487.

37 Oggionni T, Morbini P, Inghilleri S, Palladini G, Tozzi R, Vitulo P, Fenoglio C, Perlini S, Pozzi E: Time course of matrix metalloproteases and tissue inhibitors in bleomycininduced pulmonary fibrosis. Eur J Histochem 2006;50:317-325.

38 Calabresi C, Arosio B, Galimberti L, Scanziani E, Bergottini R, Annoni G, Vergani C Natural aging, expression of fibrosis-related genes and collagen deposition in rat lung. Exp Gerontol 2007;42:1003-1011.

39 Rosas IO, Ren P, Avila NA, Chow CK, Franks TJ, Travis WD, McCoy JP, May RM, Wu HP, Nguyen DM, Arcos-Burgos M, MacDonald SD, Gochuico BR: Early interstitial lung disease in familial pulmonary fibrosis. Am J Respir Crit Care Med 2007;176:698-705.
40 Lacasse Y, Selman M, Costabel U, Dalphin JC, Ando M, Morell F, Erkinjuntti-Pekkanen R, Muller N, Colby TV, Schuyler M, Cormier Y; HP Study Group: Clinical diagnosis of hypersensitivity pneumonitis. Am J Respir Crit Care Med 2003;168:952-958.

41 Erkinjuntti-Pekkanen R, Kokkarinen JI, Tukiainen HO, Pekkanen J, Husman K, Terho EO: Long-term outcome of pulmonary function in farmer's lung: a 14 year follow-up with matched controls. Eur Respir J 1997;10: 2046-2050.

42 Cottin V, Nunes H, Brillet PY, Delaval P, Devouassoux $\mathrm{G}$, Tillie-Leblond I, Israel-Biet D, Court-Fortune I, Valeyre D, Cordier JF; Groupe d'Etude et de Recherche sur les Maladies Orphelines Pulmonaires (GERM OP): Combined pulmonary fibrosis and emphysema: a distinct underrecognised entity. Eur Respir J 2005;26:586-593.

43 Jankowich MD, Polsky M, Klein M, Rounds S: Heterogeneity in combined pulmonary fibrosis and emphysema. Respiration 2008;75: 411-417.

$\checkmark 44$ Tan CSH, Tashkin DP: Supernormal maximal mid-expiratory flow rates in diffuse interstitial lung disease. Respiration 1981;42: 200-208.

45 Mauad T, Schadewijk AV, Schrumpf J, Hack CE, Fernezlian S, Garippo AL, Ejzenberg B, Hiemstra PS, Rabe KF, Dolhnikoff M; São Paulo BO Study Group: Lymphocytic inflammation in childhood bronchiolitis obliterans. Pediatr Pulmonol 2004;38:233239. 